\title{
Prognosis of neurological deficits associated with upper cervical spine injuries
}

\author{
Y Fujimura, Y Nishi, K Chiba and K Kobayashi \\ Department of Orthopaedic Surgery, School of Medicine, Keio University, 35 Shinanomachi, Shinjuku-ku, \\ Tokyo, 160 Japan
}

\begin{abstract}
We investigated the type of injury and neurological prognosis in 82 patients with an upper cervical spine injury with neurological deficits, from a total of 247 such patients that we treated, from which 11 patients who were dead on arrival had been excluded. The incidence of neurological deficits in upper cervical spine injury was $33 \%$. They were classified into three signs; cord, upper cervical nerve root, and cranial nerve signs. The types of injury accompanied by neurological deficits were burst fracture of the atlas, type II dens fracture, body fracture of the axis, type II traumatic spondylolisthesis of the axis, atlanto-occipital dislocation, and atlanto-axial dislocation. Most were unstable vertebral injuries. The four patients who died after arrival at hospital had complete tetraplegia with respiratory distress. The neurological deficit was one of paresis in the 78 patients who survived; in many, the paresis was mild with a resulting good neurological prognosis.
\end{abstract}

Keywords: upper cervical spine injuries; neurological deficit; unstable injury; respiratory distress; paresis; prognosis

\section{Introduction}

The type of injury and the clinical manifestations associated with an upper cervical spine injury differ greatly from those associated with a lower cervical spine injury because of the difference between the upper and lower cervical spine in its functional anatomy. Upper cervical spine injury with a severe neurological deficit results in death. ${ }^{1-13}$ In those who survive an upper cervical spine injury is occasionally overlooked due to lack of characteristic clinical symptoms and sometimes mild or absent neurological deficit, ${ }^{1-3,8,10-19}$ and to clouding of consciousness caused by an associated head injury. ${ }^{1-5,8,10-13,16,19}$ However, even a mild neurological deficit may likely be a sign of an unstable injury. , $^{30,11,15,16}$ It is very important as it may lead to early diagnosis and an ability to determine the therapeutic plan. It is vital to have a thorough knowledge of the type of injury and the clinical manifestations associated with an upper cervical spine injury in order to diagnose and treat this injury at an early stage. It is also important to have good knowledge of the characteristics and prognosis of the neurological deficits that may be associated with an upper cervical spine injury. The object of this study is to clarify the characteristics and prognosis of the neurological deficits associated with an upper cervical spine injury by investigating the type of injury and the therapeutic outcome.

\section{Methods}

During the 27 year period from 1966 to 1992, with the exception of 11 patients who were dead on arrival
(DOA), 247 patients with 275 injuries of the upper cervical spine were treated at the Keio University Hospital and affiliated hospitals (Table 1). Ninety-one out of 247 cases showed neurological deficits. In this study, 82 patients who presented with neurological deficits observed immediately after injury were reviewed, whereas seven patients with neurological deficits caused by concomitant injury to other locations of the spine and two patients with a delayed myelopathy were excluded from our study. The subjects consisted of 60 males and 22 females. The age averaged 29 years, ranging between 3 and 71 years, including six children who were under 10 years of age. Fifty-four had injuries caused by traffic accidents, 22 by falls, and six by a sport accident. The time from injury to arrival at the hospital was $30 \mathrm{~min}$ to 8 days. Sixty-nine of the patients arrived on the day of their injury.

Upper cervical spine injury cases were separated into those with fractures and pure dislocations depending on the type of injury. Fractures were classified as posterior arch fracture, burst fracture or lateral mass fracture of the atlas, or as dens fracture, body fracture, traumatic spondylolisthesis (hangman's fracture) or spinous process fracture of the axis. Pure dislocations were classified as atlanto-occipital dislocation (AOD), atlanto-axial dislocation (AAD) or $\mathrm{C} 2-3$ dislocation. Furthermore, dens fracture of the axis were subclassified into four subtypes: Anderson and D'Alonzo ${ }^{3}$ type I, II or III, or pediatric traumatic epiphyseal separation. Hangman's fractures were subclassified into four types: Levine and Edwards ${ }^{16}$ type I, II, IIa or III. AAD cases were divided into anterior dislocation, posterior 
Table 1 Types of upper cervical spine injury in 258 patients with 286 injuries

\begin{tabular}{|c|c|c|c|c|c|}
\hline \multirow[t]{2}{*}{ Type of injury } & \multirow[t]{2}{*}{ Dead on arrival } & \multirow{2}{*}{$\begin{array}{l}\text { Survived on } \\
\text { arrival }\end{array}$} & \multicolumn{2}{|c|}{ Associated neurological deficit } & \multirow{2}{*}{$\begin{array}{c}\text { Short term } \\
\text { survival }\end{array}$} \\
\hline & & & Isolated injury & Combined injury & \\
\hline \multicolumn{6}{|l|}{ Fracture of the atlas } \\
\hline Posterior arch fracture & & 11 & & 3 & \\
\hline Burst fracture & & 18 & 3 & 2 & \\
\hline Lateral mass fracture & & 1 & 1 & & \\
\hline \multicolumn{6}{|l|}{ Fracture of the axis } \\
\hline \multicolumn{6}{|l|}{ Dens fracture } \\
\hline Type I & & 2 & & & \\
\hline Type II & 3 & 61 & 23 & 2 & 1 \\
\hline Type III & & 30 & 8 & 4 & \\
\hline $\begin{array}{l}\text { Traumatic epiphyseal } \\
\text { separation }\end{array}$ & & 7 & 2 & & \\
\hline Body fracture & & 31 & 8 & 4 & \\
\hline \multicolumn{6}{|l|}{ Hangman's fracture } \\
\hline Type I & & 37 & & & \\
\hline Type II & 1 & 14 & 6 & 3 & \\
\hline Type IIa & & 1 & 1 & & \\
\hline Type III & 1 & 1 & 1 & & \\
\hline Spinous process fracture & & 2 & & & \\
\hline Atlanto-axial dislocation & 2 & 3 & 3 & & 2 \\
\hline Anterior dislocation & & 26 & 12 & & \\
\hline Posterior dislocation & 3 & 1 & 1 & & \\
\hline Rotatory dislocation & 1 & 1 & 1 & & \\
\hline Atlanto-axial rotatory fixation & & 19 & & & \\
\hline C2-3 dislocation & & 9 & 3 & & 1 \\
\hline
\end{tabular}

Table 2 Relationship between types of injury and neurological deficits in 82 patients

\begin{tabular}{|c|c|c|c|c|}
\hline Type of injury & $\begin{array}{c}\text { Neurological } \\
\text { deficit }\end{array}$ & $\begin{array}{l}\text { Spinal cord } \\
\text { injury }\end{array}$ & $\begin{array}{l}\text { Upper cervical } \\
\text { nerve root injury }\end{array}$ & $\begin{array}{c}\text { Cranial nerve } \\
\text { injury }\end{array}$ \\
\hline Burst fracture of the atlas & 3 & 2 & 1 & 1 \\
\hline Lateral mass fracture of the atlas & 1 & 1 & 1 & \\
\hline \multicolumn{5}{|l|}{ Dens fracture } \\
\hline Type II & 23 & 15 & 11 & 1 \\
\hline Type III & 8 & 7 & 7 & 1 \\
\hline Traumatic epiphyseal separation & 2 & 2 & 2 & \\
\hline Body fracture of the axis & 8 & 6 & 3 & 4 \\
\hline \multicolumn{5}{|l|}{ Hangman's fracture } \\
\hline Type II & 6 & 6 & 4 & 4 \\
\hline Type IIa & 1 & 1 & & \\
\hline Type III & 1 & 1 & 1 & \\
\hline Atlanto-occipital dislocation & 3 & 2 & 1 & 1 \\
\hline \multicolumn{5}{|l|}{ Atlanto-axial dislocation } \\
\hline Anterior dislocation & 12 & 9 & 4 & 2 \\
\hline Posterior dislocation & 1 & & 1 & \\
\hline Rotatory dislocation & 1 & 1 & & \\
\hline $\mathrm{C} 2-3$ dislocation & 3 & 2 & 1 & \\
\hline Posterior arch fracture of the atlas and type II dens fracture & 1 & 1 & & \\
\hline Posterior arch fracture of the atlas and type III dens fracture & 2 & 1 & 1 & \\
\hline Burst fracture of the atlas and type II dens fracture & 1 & 1 & 1 & 1 \\
\hline Burst fracture of the atlas and type II hangman's fracture & 1 & & 1 & \\
\hline Body fracture of the axis and type III dens fracture & 2 & & 2 & 2 \\
\hline Body fracture of the axis and type II hangman's fracture & 2 & 2 & 1 & \\
\hline
\end{tabular}


dislocation, rotatory dislocation or atlanto-axial rotatory fixation (AARF). According to our classification, 73 patients had isolated injuries and nine had combined injuries (Table 2).

\section{Treatment}

Thirty-two patients were treated conservatively and 50 had an operation. The halo vest was the main method used in conservative treatment. Skull traction and a cast were applied before using the halo vest. A few patients only had a cervical orthosis. The surgical procedures used were transoral anterior fusion in seven cases, anterior screw fixation (Figure 1) in 21 cases, C2-3 anterior fusion (Figure 2) in 10 cases, occipitocervical posterior fusion in two cases, and atlanto-axial posterior fusion in 10 cases.

After excluding the four patients who died, the follow-up period in the 78 patients who survived averaged 26 months, ranging between 11 and 146 months. Neurological deficits were evaluated when the patient arrived at hospital, at 1 month after injury, and at final follow-up.

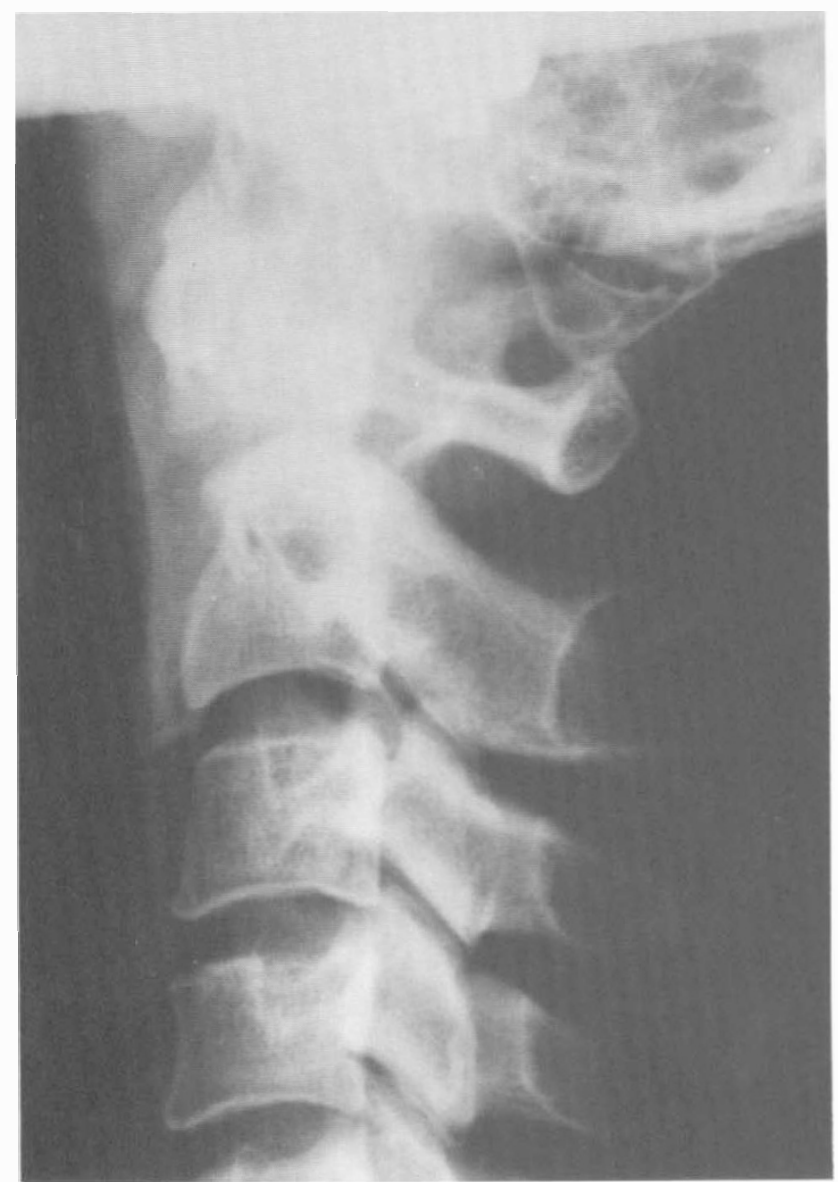

\section{Results}

The types of injury of the four patients who died after arrival at the hospital were; two with AOD (Figure 3a), one with a type II dens fracture with posterior displacement, and one patient with a $\mathrm{C} 2-3$ dislocation (Figure 3b). All died 2-54 h after injury because of complete paralysis causing respiratory failure. Including patients who were DOA, four of five patients with AOD and three out of four with posterior dislocation of the atlas on the axis died. Only one patient in each type of these injuries survived (Figure 4).

Among the 247 patients with an upper cervical spine injury, $82(33 \%)$ had neurological deficits, of which 60 (24\%) had cord signs, $43(17 \%)$ had upper cervical nerve root signs, and $17(7 \%)$ had cranial nerve signs (Table II). Fifty-two patients presented with only one symptom and 30 presented with multiple symptoms. Cord signs in the four patients who died were Frankel ${ }^{20}$ A, complete paralysis with respiratory tetraplegia. In the 56 patients who survived, cord signs were Frankel C or $\mathrm{D}$ paresis of whom two had respiratory distress (Figure 5). According to the classification of paralysis by Crandall and Batzdorf, ${ }^{21} 19$ patients had a central

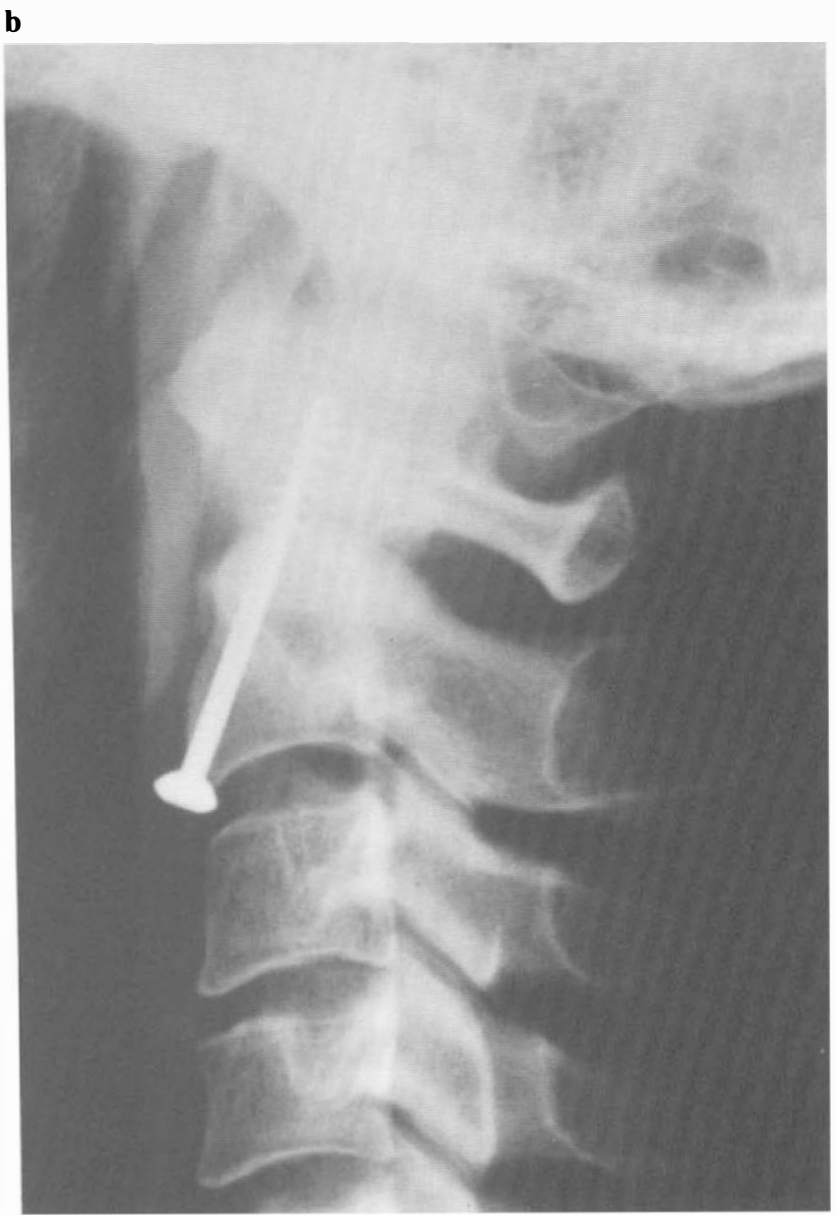

Figure 1 Anterior screw fixation for type II dens fracture. (a) This 40-year-old man had a transient quadriparesis. Preoperative lateral roentgenogram showed a type II dens fracture with anterior displacement. (b) Postoperative lateral roentgenogram showed an anatomical reduction and solid bony union 
a

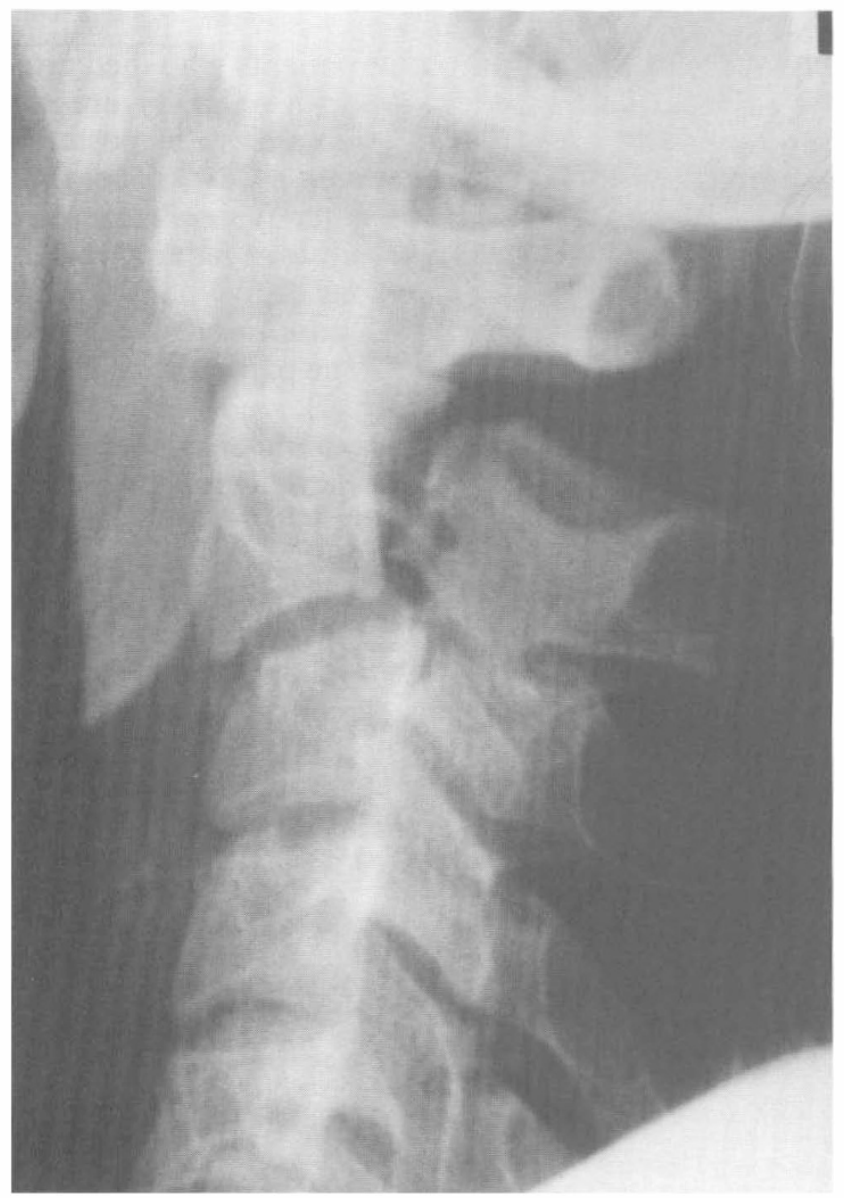

b

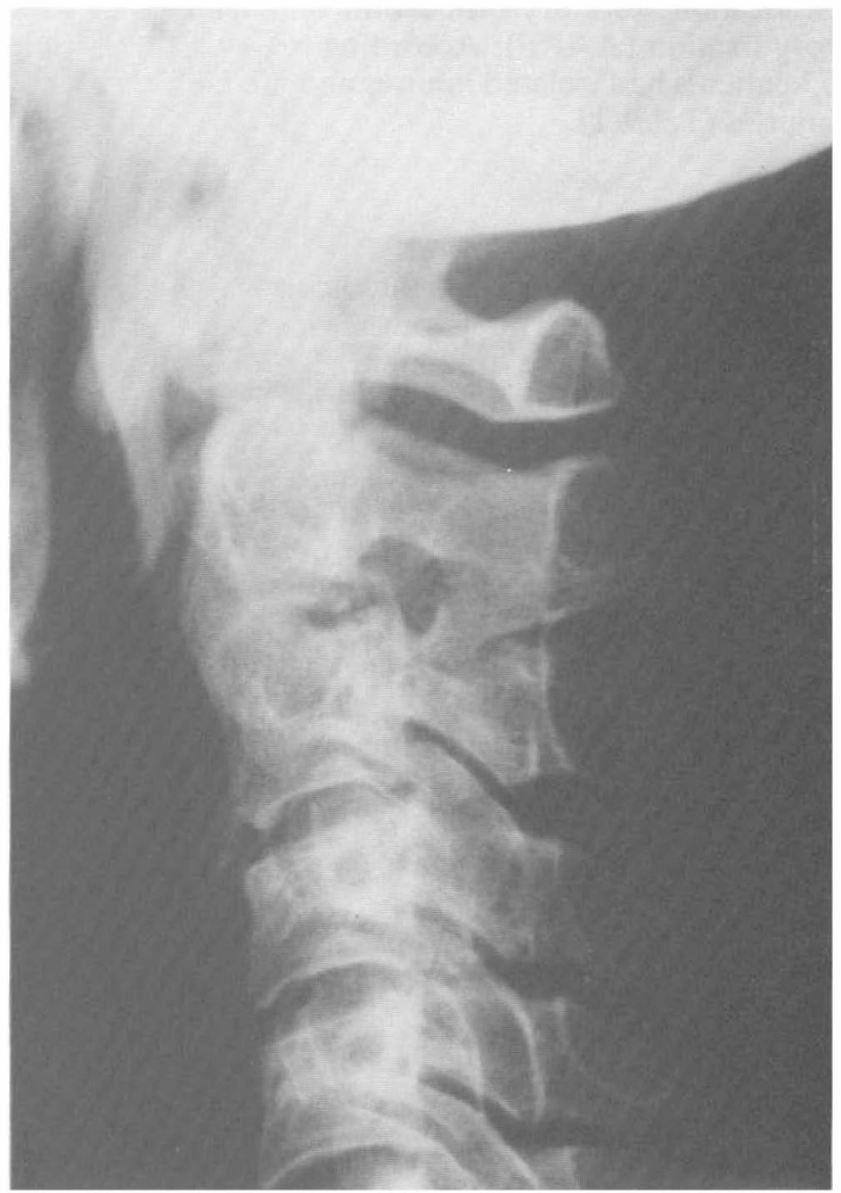

Figure 2 Anterior interbody fusion of C2-3 for type II hangman's fracture. (a) This 31-year-old man had Brown-Séquard syndrome and C2 neuralgia. Preoperative lateral roentgenogram showed a type II hangman's fracture. (b) Postoperative lateral roentgenogram showed solid bony union of the hangman's fracture

cord syndrome, 13 had a motor system syndrome, 22 had a transverse lesion syndrome, and three a BrownSéquard syndrome. Three patients who could not be classified using the above classification had a cruciate type of paralysis. ${ }^{22}$ Most of the upper cervical nerve root symptoms consisted of hyperalgesic neuralgia of the $\mathrm{C} 2$ and $\mathrm{C} 3$ dermatomes. Cranial nerve involvement was of the V and IX-XII nerves, and 10 of 17 patients had unilateral deficits.

The types of injury causing neurological deficits were studied in relationship to the symptoms they presented. In isolated injuries, the types of injury with cord signs were burst or lateral mass fractures of the atlas, type II or III dens fracture, traumatic epiphyseal separation, body fracture of the axis, type II, IIa or III hangman's fracture, $\mathrm{AOD}, \mathrm{AAD}$, and $\mathrm{C} 2-3$ dislocation. But in those with combined injuries, the types of injury with cord signs were posterior arch fracture, burst fracture of the atlas, or body fracture of the axis combined with either dens fracture or hangman's fracture (Table 2). The types of injury causing upper cervical nerve root signs were almost identical to those with cord signs, and one third of the patients with neurological deficits had both nerve root and cord symptoms. The types of injury causing cranial nerve signs did not differ much from those causing other neurological deficits. Neurological deficits did not occur in patients with only a posterior arch fracture of the atlas, type I dens fracture, type I hangman's fracture, spinous process fracture of the axis, or AARF.

Neurological recovery at 1 month after injury and final follow-up were considered in four grades, as dead, unchanged, improved or cured, based on the degree of the initial neurological deficit. Neurological recovery at 1 month after injury in the 60 patients with cord signs was evaluated as dead in four $(7 \%)$, unchanged in nine $(15 \%)$, improved in $17(28 \%)$, and cured in $30(50 \%)$. At the final follow-up, the result was: four had died $(7 \%)$, unchanged in two $(3 \%)$, improved in nine $(10 \%)$, and cured in $45(75 \%)$. Neurological recovery at 1 month after injury in the 43 patients with upper cervical nerve root signs was evaluated as unchanged in $10(23 \%)$, improved in $15(35 \%)$, and cured in 18 $(42 \%)$. At the final follow-up, it was evaluated as unchanged in four patients $(9 \%)$, improved in five $(12 \%)$, and cured in $34(79 \%)$. Neurological recovery 


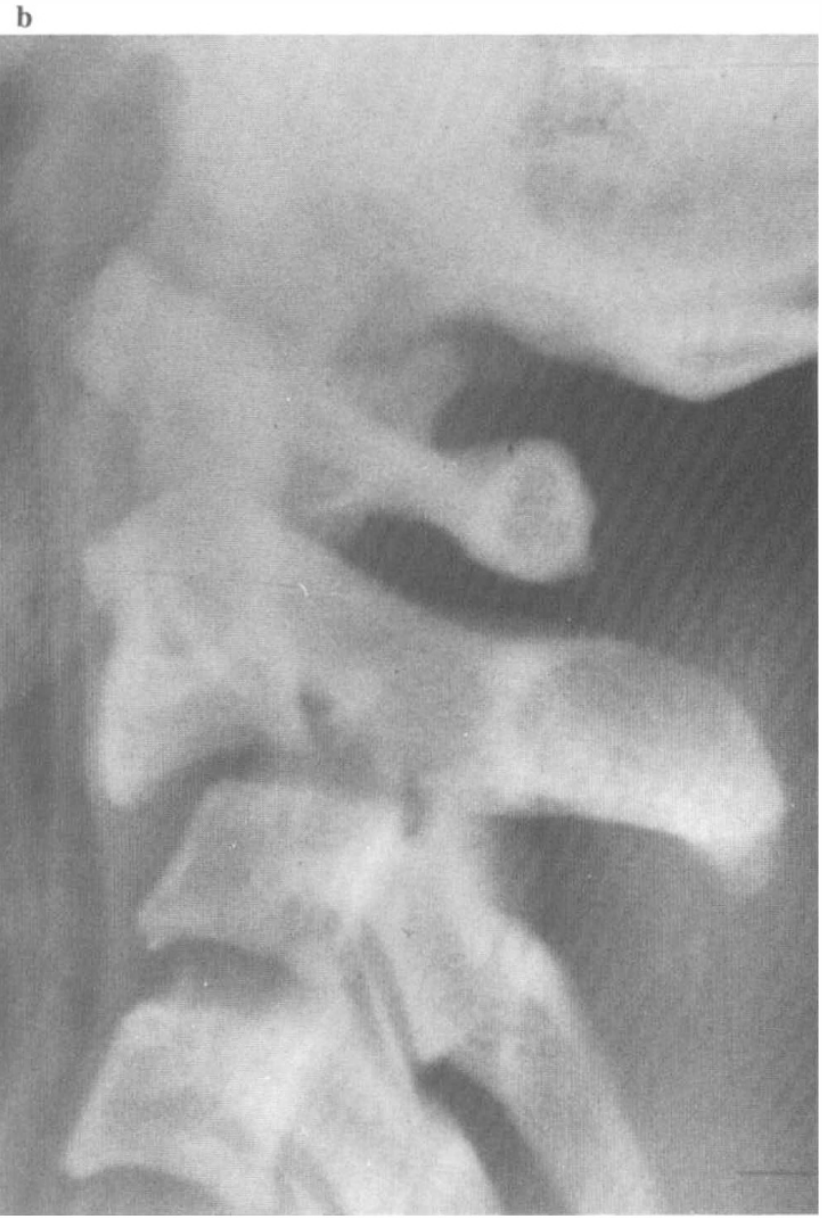

Figure 3 Upper cervical spine injury with short term survival. (a) This 5-year-old girl had a complete quadriplegia with severe respiratory distress. The lateral roentgenogram showed a dislocation of the atlanto-occipital articulation. Despite immediate intubation and control of general condition, she died $2 \mathrm{~h}$ after the injury. (b) This 25 -year-old man had a complete quadriplegia with respiratory distress. The lateral roentgenogram showed a dislocation of C2-3. Despite immediate intubation, reduction of the dislocation using skull traction and control of general condition, he died $54 \mathrm{~h}$ after the injury

at 1 month after injury in the 17 patients with cranial nerve signs was evaluated as unchanged in five $(29 \%)$, improved in eight $(47 \%)$, and cured in four $(24 \%)$. At the final follow-up, it was evaluated as unchanged in one patient (6\%), improved in two (12\%), and cured in $14(82 \%)$. Neurological recovery was achieved in $70 \%$ or more of the patients at 1 month after injury, and in $90 \%$ or more at the final follow-up independent of the type of neurological deficit (Table 3). Furthermore, many of the patients were cured by the time of the final follow-up, which indicates that the neurological prognosis had been good.

\section{Discussion}

The characteristics of the neurological deficits associated with an upper cervical spine injury are lethal in severe cases. However, in patients who survive, neurological deficits occur infrequently and, if they do occur, they are often mild. ${ }^{1-19}$ The reason for this lies in the anatomical relationship between the upper cervical spine and the cervical spinal cord. Severe cervical spinal cord injury above $\mathrm{C} 4$ spinal cord segment is frequently associated with respiratory failure and is lethal. ${ }^{4-6}$ However, the sagittal diameter of the spinal canal in the upper cervical region becomes wider above C2-3 relative to the lower cervical region. ${ }^{23}$ In addition, the spinal cord can move up and down according to the movement of the cervical spine, and the spinal cord itself can expand and contract. ${ }^{24}$ This should allow the upper cervical spinal cord to resist injury to some extent despite narrowing of the sagittal diameter of the spinal canal, or the cervical spine being vertically dislocated. Thus neurological deficits can be absent or be mild. Neurological deficits that occur under these circumstances, although mild, may be a consequence of an unstable injury which may result in death if left unattended..$^{9,13,25}$ Therefore it is necessary to have sufficient knowledge of the neurological deficits that are characteristic of these types of injury. The results of the investigation presented in this study clarify the characteristics of the neurological deficits associated with an upper cervical spine injury according to the type of injury and its neurological prognosis. 

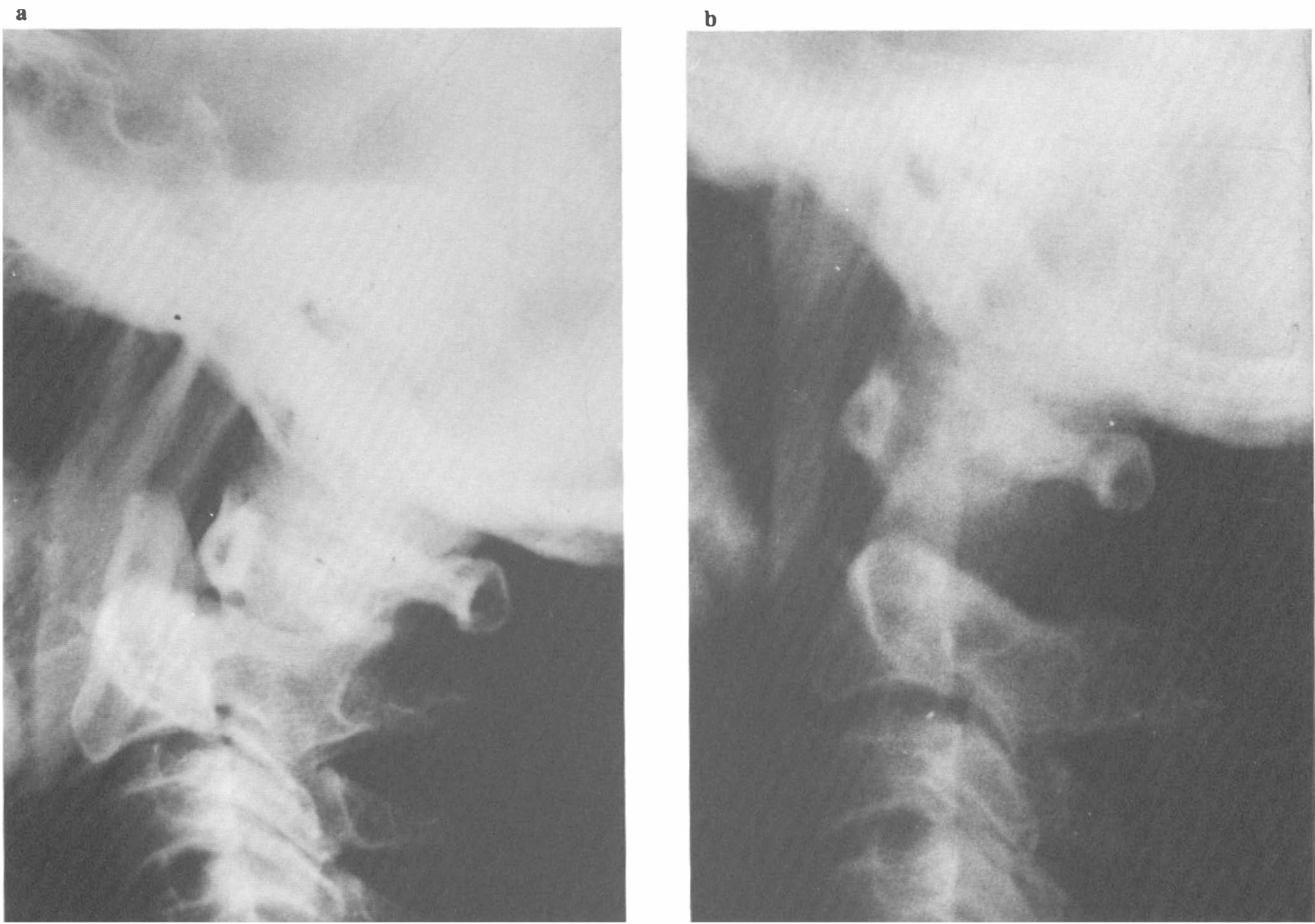

Figure 4 Posterior dislocation of the atlas on the axis with survival. (a) This 54-year-old man complained of only a C2 neuralgia. The lateral roentgenogram on admission showed a posterior dislocation of the atlas on the axis. (b) Skull traction was applied and manual closed reduction of the dislocation was performed under image intensifier control. The lateral roentgenogram after reduction showed a normal position of the atlas with respect to the axis

Very severe neurological deficits associated with an upper cervical injury can cause respiratory failure, with a fatal outcome. Including those who were DOA, four out of five with AOD and three out of four with a posterior dislocation of the atlas on the axis died.

Regarding pure dislocations, two types were frequently lethal. These results are in accordance with the reports of many previous studies. ${ }^{4,5,7,9,13,26-29}$ The result that $20-50 \%$ of patients with neurological deficits which survived were cured at 1 month after injury indicates that the neurological deficits were transient in many of these patients. All who had cord signs were limited to paresis which was quite mild. The types of injury that were associated with neurological deficits were burst fracture of the atlas, type II and III dens fractures, body fracture of the axis, type II hangman's fracture, $\mathrm{AOD}$, and $\mathrm{AAD}$. Most of them were unstable injuries. However, $50 \%$ of the unstable injuries were not accompanied by neurological deficits. Posterior arch fracture of the atlas, type I dens fracture, type I hangman's fracture, spinous process fracture of the axis, and AARF were not accompanied by neurological deficits. These facts suggest that even transient or mild neurological deficits associated with upper cervical spine injury may be a sign of unstable injury. Since many of these patients had only mild paresis, a good neurological prognosis can be expected. Thus it is important to reach an accurate diagnosis and to select an appropriate treatment for patients with an upper cervical spine injury with associated neurological deficits.

\section{Conclusions}

Eighty-two patients with an upper cervical spine injury associated with neurological deficits were studied. Very severe neurological deficits caused respiratory failurewhich often led to a fatal outcome. In patients who survived, the neurological deficits were a sign of an unstable injury; many had a mild paresis, with a good neurological prognosis. 


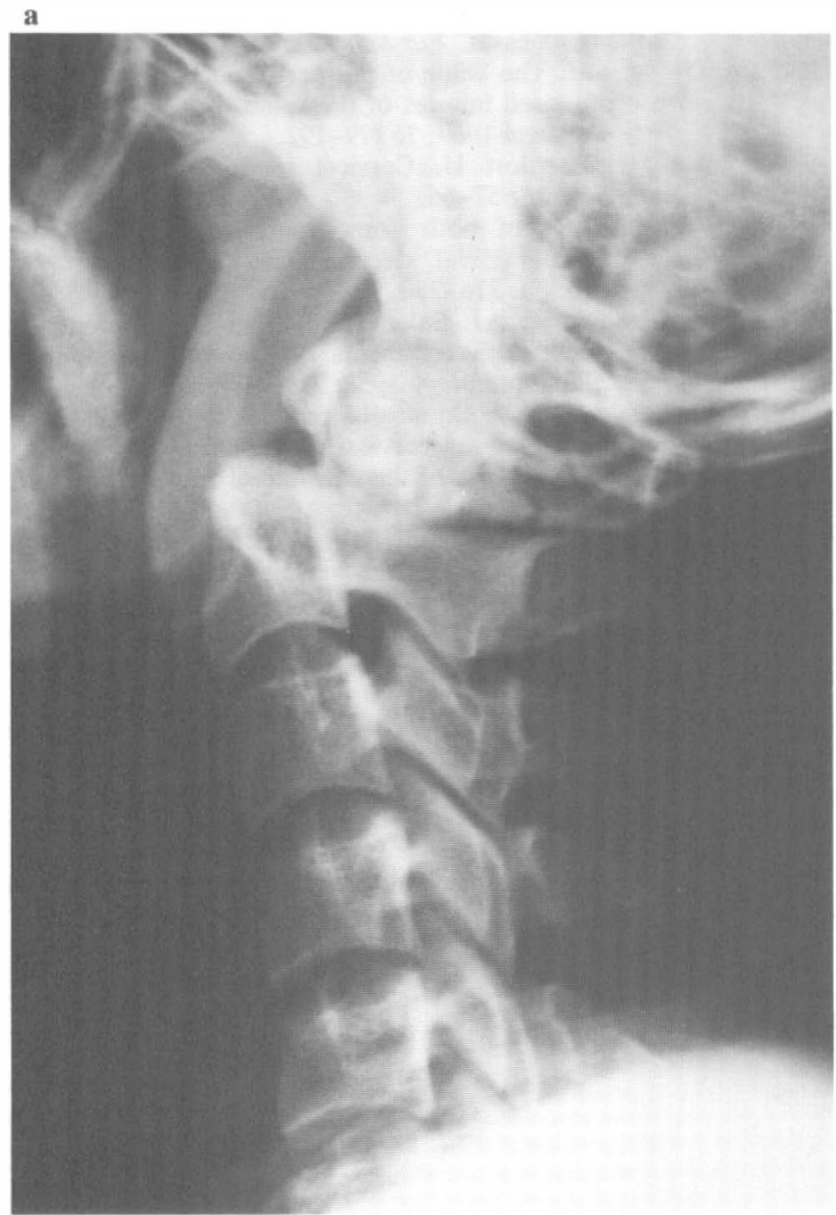

b

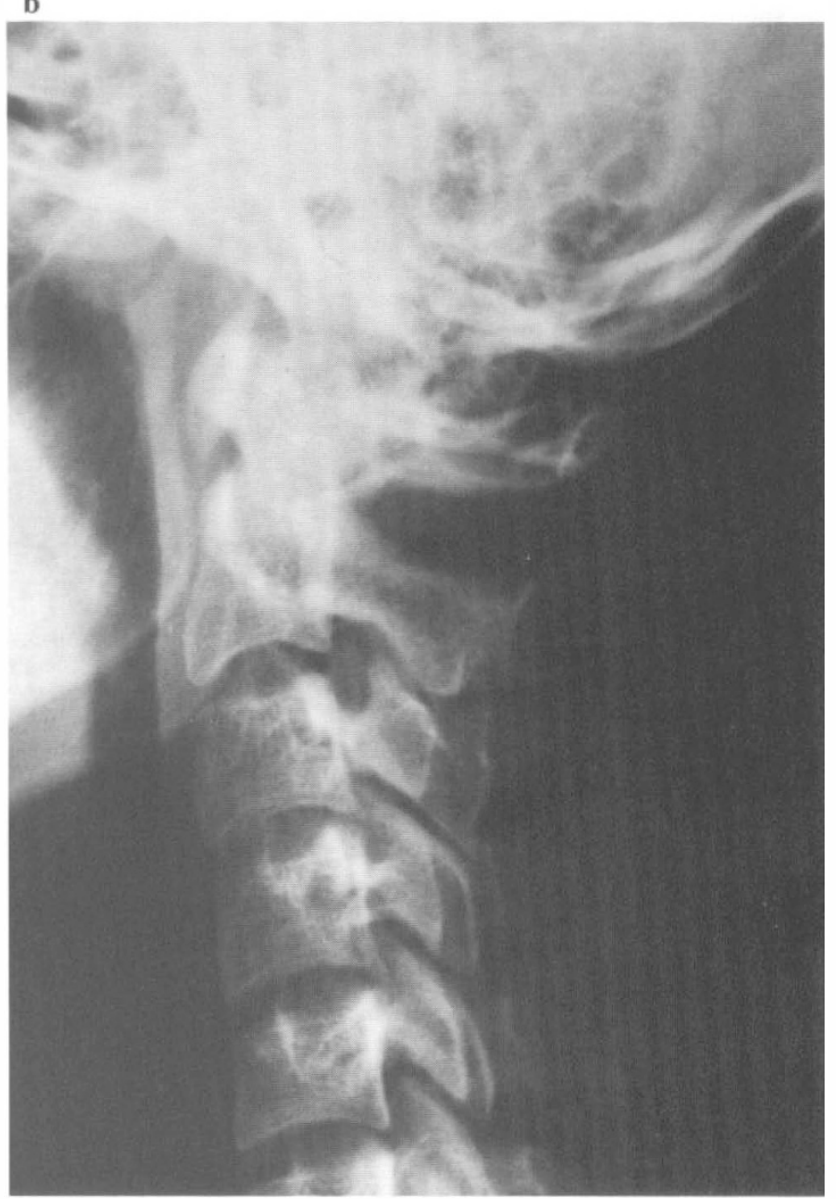

Figure 5 Quadriparesis with respiratory distress due to type II dens fracture. (a) This 17-year-old woman had a quadriparesis with respiratory distress. The lateral roentgenogram showed a type II dens fracture with posterior displacement and posterior arch fracture of the atlas. (b) The fracture was reduced and neurological deficit was fully recovered after applying a halo vest. The lateral roentgenogram showed an anatomical reduction and solid bony union

Table 3 Neurological recovery

\begin{tabular}{|c|c|c|c|c|c|c|c|c|}
\hline \multirow[t]{2}{*}{ Neurological deficit } & \multicolumn{4}{|c|}{1 month after injury } & \multicolumn{4}{|c|}{ Final follow-up } \\
\hline & Dead & Unchanged & Improved & Cured & Dead & Unchanged & Improved & Cured \\
\hline $\begin{array}{l}\text { Spinal cord injury } \\
\qquad(n=60)\end{array}$ & $\begin{array}{c}4 \\
(7 \%)\end{array}$ & $\begin{array}{c}9 \\
(15 \%)\end{array}$ & $\begin{array}{c}17 \\
(28 \%)\end{array}$ & $\begin{array}{c}30 \\
(50 \%)\end{array}$ & $\begin{array}{c}4 \\
(7 \%)\end{array}$ & $\begin{array}{c}2 \\
(3 \%)\end{array}$ & $\begin{array}{c}9 \\
(15 \%)\end{array}$ & $\begin{array}{c}45 \\
(75 \%)\end{array}$ \\
\hline $\begin{array}{l}\text { Upper cervical nerve root injury } \\
\qquad(n=43)\end{array}$ & $\begin{array}{c}0 \\
(0 \%)\end{array}$ & $\begin{array}{c}10 \\
(23 \%)\end{array}$ & $\begin{array}{c}15 \\
(35 \%)\end{array}$ & $\begin{array}{c}18 \\
(42 \%)\end{array}$ & $\begin{array}{c}0 \\
(0 \%)\end{array}$ & $\begin{array}{c}4 \\
(9 \%)\end{array}$ & $\begin{array}{c}5 \\
(12 \%)\end{array}$ & $\begin{array}{c}34 \\
(79 \%)\end{array}$ \\
\hline $\begin{array}{l}\text { Cranial nerve injury } \\
\quad(n=17)\end{array}$ & $\begin{array}{c}0 \\
(0 \%)\end{array}$ & $\begin{array}{c}5 \\
(29 \%)\end{array}$ & $\begin{array}{c}8 \\
(47 \%)\end{array}$ & $\begin{array}{c}4 \\
(24 \%)\end{array}$ & $\begin{array}{c}0 \\
(0 \%)\end{array}$ & $\begin{array}{c}1 \\
(6 \%)\end{array}$ & $\begin{array}{c}2 \\
(12 \%)\end{array}$ & $\begin{array}{c}14 \\
(82 \%)\end{array}$ \\
\hline
\end{tabular}

\section{References}

1 Jefferson G. Fracture of the atlas vertebra: report of four cases, and a review of those previously recorded. Br J Surg 1920; 7 : 407-422.

2 Schneider RC, Livingston KE, Cave AJF, Hamilton G. 'Hangman's fracture' of the cervical spine. J Neurosurg 1965; 22: 141-154.

3 Anderson LD, D'Alonzo RT. Fractures of the odontoid process of the axis. J Bone Joint Surg Am 1974; 56: 1663-1674.
4 Alker JA Jr et al. Postmortem radiology of head and neck injuries in fatal traffic accidents. Radiology 1975; 114: 611-617.

5 Alker GJ Jr, Oh YS, Leslie EV. High cervical spine and craniocervical junction injuries in fatal traffic accidents: a radiological study. Orthop Clin North Am 1978; 9: 1003-1010.

6 Stauffer ES, Bell GD. Traumatic respiratory quadriplegia and pentaplegia. Orthop Clin North Am 1978; 9: 1081-1089.

7 Bucholz RW, Burkhead WZ. The pathological anatomy of fatal atlanto-occipital dislocations. J Bone Joint Surg Am 1979; 61: 248-250.

8 Bohlman HH. Acute fractures and dislocations of the cervical 
spine: an analysis of three hundred hospitalized patients and review of the literature. J Bone Joint Surg Am 1979; 61: 1119-1142.

9 Dublin AB, Marks WM, Weinstock D, Newton TH. Traumatic dislocation of the atlanto-occipital articulation (AOA) with short-term survival. J Neurosurg 1980; 52: 541-546.

10 Effendi B et al. Fractures of the ring of the axis: a classification based on the analysis of 131 cases. J Bone Joint Surg Br 1981; 63: $319-327$

11 Levine AM, Edwards CC. Treatment of injuries in the $\mathrm{C} 1-\mathrm{C} 2$ complex. Orthop Clin North Am 1986; 17: 31-44.

12 Fujii E, Kobayashi K, Hirabayashi K. Treatment in fractures of the odontoid process. Spine 1988; 13: 604-609.

13 Montane I, Eismont FJ, Green BA. Traumatic occipitoatlanta dislocation. Spine 1991; 16: 112-116.

14 Fielding JW, Hawkins RJ. Atlanto-axial rotatory fixation: fixed rotatory subluxation of the atlanto-axial joint. J Bone Joint Surg Am 1977; 59: 37-44.

15 Francis WR et al. Traumatic spondylolisthesis of the axis. J Bone Joint Surg Br 1981; 63: 313-318.

16 Levin AM, Edwards CC. The management of traumatic spondylolisthesis of the axis. J Bone Joint Surg Am 1985; 67: 217-226.

17 Dickman CA, Hadley MN, Bowner C, Sonntag VKH Neurosurgical management of acute atlas-axis combination fractures: a review of 25 cases. J Neurosurg 1989; 70: 45-49.

18 Levine AM, Edwards CC. Fractures of the atlas. J Bone Joint Surg Am 1991; 73: 680-691.

19 Chiba $\mathrm{K}$ et al. Anterior screw fixation for odontoid fracture clinical results in 45 cases. Eur Spine J 1993; 2: 76-81.

20 Frankel HL et al. The value of postural reduction in the initial management of closed injuries of the spine with paraplegia and tetraplegia. Paraplegia 1969; 7 : 179-192.

21 Crandall PH, Batzdorf U. Cervical spondylotic myelopathy. J Neurosurg 1966; 25: 57-66.

22 Bell HS. Paralysis of both arms from injury of the upper portion of the pyramidal decussation: 'cruciate paralysis'. J Neurosurg 1970; 33: 376-380.

23 Wholey MH, Bruwer AJ, Baker HL Jr. The lateral roentgenogram of the neck: with comments on the atlanto-odontoidbasion relationship. Radiology 1958; 71: 350-356.

24 Adams CBT, Logue V. Studies in cervical spondylotic myelopathy: I. movement of the cervical roots, dura and cord, and their relation to the course of the extrathecal roots. Brain 1971; 94: 557-568.

25 Spence KF Jr, Decker S, Sell KW. Bursting atlantal fracture associated with rupture of the transverse ligament. J Bone Joint Surg Am 1970; 52: 543-549.

26 Gabrielsen TO, Maxwell JA. Traumatic atlanto-occipital dislocation: with case report of a patient who survived. Am J Roentgenol 1966; 97: 624-629.

27 Haralson RH III, Boyd HB. Posterior dislocation of the atlas on the axis without fracture: report of a case. J Bone Joint Surg Am 1969; 51: 561-566.

28 Evarts CM. Traumatic occipito-atlantal dislocation: report of a case with survival. J Bone Joint Surg Am 1970; 52: 1653-1660.

29 Patzakis MJ et al. Posterior dislocation of the atlas on the axis a case report. J Bone Joint Surg Am 56: 1260-1262. 